\title{
Determining resistance to Fusarium verticillioides and fumonisin accumulation in African maize inbred lines resistant to Aspergillus flavus and aflatoxins
}

\author{
Lindy Joy Rose (iD) Sheila Okoth - Ilze Beukes - Abigael Ouko - Marili Mouton • \\ Bradley Charles Flett · Dan Makumbi · Altus Viljoen
}

Received: 9 May 2016/Accepted: 9 March 2017/Published online: 25 March 2017

(C) Springer Science+Business Media Dordrecht 2017

\begin{abstract}
Fusarium verticillioides and Aspergillus flavus cause Fusarium ear rot (FER) and Aspergillus ear rot (AER) of maize, respectively. Both pathogens are of concern to producers as they reduce grain yield and affect quality. F. verticillioides and A. flavus also contaminate maize grain with the mycotoxins fumonisins and aflatoxins, respectively, which has been associated with mycotoxicosis in humans and animals. The occurrence of common resistance mechanisms to FER and AER has been reported. Hence, ten Kenyan inbred lines resistant to AER and aflatoxin accumulation were evaluated for resistance to FER, $F$. verticillioides colonisation and fumonisin accumulation; and compared to nine South African lines
\end{abstract}

L. J. Rose $(\varangle) \cdot$ I. Beukes · M. Mouton · A. Viljoen ( $\square)$ Department of Plant Pathology, Stellenbosch University, Private Bag X1, Matieland 7602, South Africa e-mail: lindym@sun.ac.za

A. Viljoen

e-mail: altus@sun.ac.za

S. Okoth $\cdot$ A. Ouko

School of Biological Sciences, University of Nairobi,

P. O. Box 30197-00100, Nairobi, Kenya

B. C. Flett

Agricultural Research Council - Grain Crops Institute,

Private Bag X1251, Potchefstroom 2520, South Africa

D. Makumbi

International Maize and Wheat Improvement Center

(CIMMYT), P.O. Box 1041-00621, Nairobi, Kenya resistant to FER and fumonisin accumulation. Field trials were conducted at three localities in South Africa and two localities in Kenya. FER severity was determined by visual assessment, while $F$. verticillioides colonisation and fumonisin content were quantified by real-time PCR and liquid chromatography tandem mass spectrometry, respectively. Significant genotype $\mathrm{x}$ environment interactions was determined at each location $(P \leq 0.05)$. Kenyan inbred CML495 was most resistant to FER and $F$. verticillioides colonisation, and accumulated the lowest concentration of fumonisins across localities. It was, however, not significantly more resistant than Kenyan lines CML264 and CKL05015, and the South African line RO549 W, which also exhibited low FER severity ( $\leq 5 \%)$, fungal target DNA $\left(\leq 0.025 \mathrm{ng} \mu \mathrm{L}^{-1}\right)$ and fumonisin levels $\left(\leq 2.5 \mathrm{mg} \mathrm{kg}^{-1}\right)$. Inbred lines resistant to AER and aflatoxin accumulation appear to be promising sources of resistance to $F$. verticillioides and fumonisin contamination.

Keywords Fusarium ear rot - Aspergillus ear rot . Resistance $\cdot$ Mycotoxins $\cdot$ Maize inbred lines

\section{Introduction}

Fusarium ear rot (FER) and Aspergillus ear rot (AER) are important diseases of maize in Africa as they reduce both grain yield and quality. The diseases are caused by 
the fungal pathogens Fusarium verticillioides (Sacc.) Nirenberg and Aspergillus flavus Link:Fr., respectively. These fungi produce toxic secondary metabolites in maize grain, called mycotoxins, which pose a serious threat to human and animal health. Fumonisins, produced by $F$. verticillioides, has been associated with oesophageal cancer of human adults in South Africa, Italy, Iran and China (Franceshi et al. 1990; Rheeder et al. 1992; Shephard et al. 2000; Li et al. 2001) and neural tube defects in infants (Hendricks 1999; Missmer et al.2006). Aflatoxins, produced by A. flavus, are potent carcinogens and have resulted in severe cases of aflatoxicosis in Kenya which led to human fatalities (Williams et al. 2004). It also reduced the height of children in Benin and Togo (Gong et al. 2002) and suppressed the immune system of both humans and animals (Williams et al. 2004). Fumonisins and aflatoxins are poisonous to livestock, with fumonisins causing equine leukoencephalomalacia (Kellerman et al. 1990) and porcine pulmonary oedema syndrome (Colvin and Harrison 1992), while aflatoxins cause aflatoxicosis in cattle and sheep. Mycotoxin levels in food and feed are strictly regulated in the USA and European Union (FDA 2000; European Commission, 2007). In South Africa, the maximum tolerable level for aflatoxin levels in foods is $10 \mu \mathrm{g} / \mathrm{kg}$ (Government Gazette 2004). Recently, South Africa has amended regulations regarding the tolerances for fungusproduced toxins in foodstuffs by limiting fumonisins in maize grain, intended for further processing, to $4000 \mu \mathrm{g} / \mathrm{kg}$ while processed products, ready for human consumption, may not contain more than $2000 \mu \mathrm{g} / \mathrm{kg}$ of fumonisins (Goverment Gazette 2016). Studies conducted in rural areas of South Africa indicated that fumonisin levels in maize grain often exceed tolerable limits enforced in Europe and USA (Shephard et al. 2007; Shephard 2008; Ncube et al. 2011).

Fumonisins and aflatoxins can co-occur on maize grain (Fandohan et al. 2005), but the nature of the interaction between their respective producers, $F$. verticillioides and $A$. flavus, is still unclear. It has been suggested that kernels infected by $F$. verticillioides may become resistant to subsequent infection by A. flavus (Wicklow et al. 1988). Marin et al. (1998) found that $F$. verticillioides outgrew A. flavus over a range of temperatures and reduced its growth in vitro. This supports the hypothesis of a competitive relationship between the two species, possibly for the same resources or niche on maize ears (Marin et al. 1998). Giorni et al.
(2009), however, demonstrated that these fungi occupied different ecological niches based on carbon source utilization patterns in vitro. When plants were coinoculated with $F$. verticillioides and A. flavus, their grain contained significantly less aflatoxins than grain from plants that were inoculated with A. flavus only (Zummo and Scott 1992). Conversely, Abbas et al. (2006) reported that fumonisin and aflatoxin levels in hybrids naturally infected with $F$. verticillioides and $A$. flavus were positively correlated. These results suggest that both species can grow on the same plant without necessarily competing for the same resources if host plants are highly susceptible.

The planting of resistant maize cultivars, as part of an integrated disease management strategy, is considered an efficient approach to reduce FER and AER and minimize the risk of mycotoxin accumulation in maize. Zummo and Scott (1992) found that infection with $F$. verticillioides did not prevent the identification of genotypes resistance to A. flavus. The strong positive correlations between FER and AER severity, and also between AER and aflatoxin accumulation (RobertsonHoyt et al. 2007), suggest that selecting maize germplasm for reduced FER should reduce AER and aflatoxin contamination. Quantitative trait loci (QTLs) associated with resistance to FER, AER, fumonisin and aflatoxin accumulation suggest that resistance to FER, AER and their associated mycotoxins may be genetically linked (Robertson-Hoyt et al. 2007). Xiang et al. (2010) further revealed that QTLs associated with resistance to FER, AER and Gibberella ear rot (GER), caused by Fusarium graminearum Schwabe, clustered in the same chromosome regions while Wisser et al. (2006) also reported QTLs to different diseases clustered in the maize genome. In a study evaluating the defense-responses of other FER-causing Fusarium spp. and A. flavus, Lanubile et al. (2015) demonstrated the overlap or community of genes and regulation pathways activated in response to infection by these pathogens.

Enhancing host-plant resistance in crops can be expedited by the identification of sources of resistance, preferably in locally-adapted breeding materials. Resistance, if durable under different growing conditions and in different maize production areas, can then be introduced into high-yielding and agronomically superior planting material that is susceptible to FER and fumonisin contamination. Plant resistance provides a number of advantages compared to other disease management options, such as ease of handling, 
affordability and being environmentally friendly. Maize inbred lines and hybrids have thus been evaluated worldwide for resistance to either FER/fumonisin contamination or AER/aflatoxin contamination (Clements and White 2004; Robertson et al. 2006; Afolabi et al. 2007; Eller et al. 2010; Henry et al. 2009; Parsons and Munkvold 2012), but seldom against both.

FER and fumonisin contamination is considered an important constraint to maize production in South Africa. AER and aflatoxin contamination, on the contrary, poses a limited threat in temperate maize production areas, and affects only subsistence farmers in northern KwaZulu-Natal where maize-growing conditions are subtropical. In eastern Africa, however, plant protection efforts are focused almost entirely on AER and aflatoxin contamination of maize, with little to no information available on other ear rot pathogens and their mycotoxins, including $F$. verticillioides. The objectives of this study, therefore, were to evaluate Kenyan inbred lines resistant to AER and aflatoxin accumulation for resistance to FER and fumonisin accumulation in South Africa and Kenya and to compare resistant Kenyan inbred lines to well-characterised FER/fumonisin-resistant South African inbred lines.

\section{Materials and methods}

Plant material evaluated

Ten Kenyan inbred lines, previously characterised as resistant to AER and aflatoxin accumulation (Dr. D. Makumbi, personal communication), and nine maize inbred lines from South Africa, previously characterised as resistant to FER and fumonisin accumulation (Small et al. 2012; Rose et al. 2016) were used in this study (Table 1). Additionally, two South African inbred lines susceptible to FER and fumonisin accumulation were included as susceptible checks. The South African inbred lines were provided by the Agricultural Research Council-Grain Crops Institute (ARC-GCI) in Potchefstroom, South Africa, while the Kenyan inbred lines were provided by the International Maize and Wheat Improvement Center (CIMMYT) in Nairobi, Kenya.

Field trials

Field trials in South Africa were conducted at Potchefstroom (grid ref.: $26^{\circ} 73^{\prime} \mathrm{S}, 27^{\circ} 07^{\prime} \mathrm{E}$; altitude,
$1349 \mathrm{~m}$ ) in the Northwest province and Vaalharts (grid ref.: $27^{\circ} 95^{\prime} \mathrm{S}, 24^{\circ} 83^{\prime} \mathrm{E}$; altitude, $1180 \mathrm{~m}$ ) in the Northern Cape province during the 2012/13 maize growing season. A trial was also conducted at Makhatini (grid ref.: $22^{\circ} 39^{\prime} \mathrm{S}, 32^{\circ} 17^{\prime} \mathrm{E}$; altitude, $77 \mathrm{~m}$ ) in the KwaZulu-Natal province of South Africa during 2013, as this locality represents the most tropical maize-growing site in the country. In Kenya, screening trials were conducted in 2013 and performed at the Kenya Agricultural and Research Institute (KARI) stations of Katumani (grid ref.: $1^{\circ} 35^{\prime} \mathrm{S}, 37^{\circ} 14^{\prime} \mathrm{E}$; altitude $1600 \mathrm{~m}$ ) and Kiboko (grid ref.: $2^{\circ} 15^{\prime} \mathrm{S}, 37^{\circ} 75^{\prime} \mathrm{E}$; altitude $975 \mathrm{~m}$ ). These stations lie within the Machakos County in the semiarid eastern Kenya, and has been shown to be an aflatoxin hot spot (Lewis et al. 2005).

Standard procedures to prepare fields were followed at all the trial locations. Maize kernels were manually planted (two seeds per hill) in double-row 10 -m plots, with an intra-row spacing of $0.3 \mathrm{~m}$ and an inter-row spacing of $1 \mathrm{~m}$. The trials were planted using a randomised complete block design and replicated three times, with experimental plots thinned to 33 plants per plot 3 weeks after emergence. The Potchefstroom and Makhatini trials were conducted under dryland conditions and supplemented with overhead irrigation when required, while the trial conducted at Vaalharts was flood irrigated weekly. The trials conducted at Katumani and Kiboko were drip irrigated.

Fungal isolates and production of inoculum

Country-specific, well-characterised toxigenic isolates were used to generate inoculum. Isolates obtained from the areas where the field trials were conducted were used wherever possible. Isolates of $F$. verticillioides used to inoculate South African trials consisted of GCI 315 and GCI 790, which were originally isolated from infected maize in Ndwedwe (KwaZuluNatal) and Rushof (Northern Cape), respectively. The prolific fumonisin $\mathrm{B}_{1}$ producer MRC 826 (Rheeder et al. 1992), isolated from infected maize in the Transkei region (South Africa), was also included to ensure a high level of pathogenicity and fumonisin production. Three Kenyan isolates of $F$. verticillioides; UONK005, UONK038 and UONK048 were used to inoculate the Kenyan field trials and are held in the culture collection of the University of Nairobi, 
Table 1 Maize inbred lines evaluated for resistance to Fusarium ear rot, Fusarium verticillioides colonisation and fumonisin accumulation in South Africa and Kenya during the 2012/13 maize growing seasons

\begin{tabular}{|c|c|c|c|c|}
\hline Inbred line name & Line code $\mathrm{a}^{\mathrm{a}}$ & Institution $^{\mathrm{b}}$ & $\begin{array}{l}\text { FER/fumonisin } \\
\text { status }\end{array}$ & $\begin{array}{l}\text { AER/aflatoxin } \\
\text { status }\end{array}$ \\
\hline CB-222 & 1 & ARC-GCI-South Africa & Resistant $^{\mathrm{c}}$ & Unknown \\
\hline CB-248 & 2 & ARC-GCI-South Africa & Resistant $^{\mathrm{c}}$ & Unknown \\
\hline CKL05003 & 3 & CIMMYT_Kenya & Unknown & Resistant \\
\hline CKL05015 & 4 & CIMMYT_Kenya & Unknown & Resistant \\
\hline CKL05019 & 5 & CIMMYT_Kenya & Unknown & Resistant \\
\hline CKL05022 & 6 & CIMMYT_Kenya & Unknown & Resistant \\
\hline CML182 & 7 & CIMMYT_Zimbabwe & Resistant $^{\mathrm{c}}$ & Unknown \\
\hline CML247 & 8 & CIMMYT_Kenya & Unknown & Resistant \\
\hline CML264 & 9 & CIMMYT_Kenya & Unknown & Resistant \\
\hline CML390 & 10 & ARC-GCI-South Africa & Resistant $^{\mathrm{c}}$ & Unknown \\
\hline CML444 & 11 & ARC-GCI-South Africa & Resistant $^{\mathrm{c}}$ & Unknown \\
\hline CML495 & 12 & CIMMYT_Kenya & Unknown & Resistant \\
\hline $\mathrm{I} 137 \mathrm{tnW}$ & 13 & ARC-GCI-South Africa & Susceptible $^{c}$ & Unknown \\
\hline $\begin{array}{l}\text { La Posta Seq C7-F103-2-1-1- } \\
\text { 1xMIRTC5 Bco F80-4-2-1-1-1- } \\
\text { 3-1-B-B-B (La Posta) }\end{array}$ & 14 & CIMMYT_Kenya & Unknown & Resistant \\
\hline $\begin{array}{l}\text { MIRTC5 Bco F78-2-2-1-1- } \\
\text { 1xDERRc2 15-3-7-1-1-B-B-B- } \\
\text { B (MIRTC5) }\end{array}$ & 15 & CIMMYT_Kenya & Unknown & Resistant \\
\hline $\begin{array}{l}\text { P502c2-185-3-4-2-3-B-2-B-B-B- } \\
\text { B-B-B (P502c2) }\end{array}$ & 16 & CIMMYT_Kenya & Unknown & Resistant \\
\hline R119 W & 17 & ARC-GCI-South Africa & Resistant $^{\mathrm{c}}$ & Unknown \\
\hline $\mathrm{R} 2565 \mathrm{y}$ & 18 & CIMMYT_Zimbabwe & Susceptible $^{c}$ & Unknown \\
\hline RO549W & 19 & CIMMYT_Zimbabwe & Resistant $^{\mathrm{c}}$ & Unknown \\
\hline US2540W & 20 & ARC-GCI-South Africa & Resistant $^{c}$ & Unknown \\
\hline VO617y-2 & 21 & CIMMYT_Zimbabwe & Resistant $^{\mathrm{c}}$ & Unknown \\
\hline
\end{tabular}

${ }^{a}$ Designated line code for the inbred lines used in this study

b Agricultural Research Council-Grain Crops Institute (ARC-GCI), CIMMYT-International Maize and Wheat Improvement Center

c According to Small et al. (2012) and Rose et al. (2016)

School of Biological Sciences. These isolates were obtained from infected maize from the highly contaminated Nandi district.

Inoculum for disease screening trials was prepared by growing the $F$. verticillioides isolates in Armstrong liquid medium (Booth 1971). Conidial suspensions were further prepared according to Small et al. (2012) and the concentration was adjusted to $1 \times 10^{6}$ spores $\mathrm{mL}^{-1}$ for each $F$. verticillioides isolate. Equal volumes of the three conidial suspensions per country were then combined to produce the final inoculum. The inoculum was kept at $4{ }^{\circ} \mathrm{C}$ prior to and during the inoculation process, and inoculum viability was confirmed by fungal growth on potato dextrose agar following field inoculations.
Inoculation and assessment of disease severity

Maize ears were inoculated at the R2 blister stage (Ritchie et al. 1993) according to the method described by Small et al. (2012). Once the inoculated ears reached physiological maturity and the grain dried to $12-18 \%$ moisture they were manually harvested, dehusked and FER symptoms visually assessed. Disease severity was determined by the percentage of each ear covered by visible symptoms of FER (Clements and White 2004). Maize ears were then mechanically shelled and bulked per experimental plot. A 250-g kernel sample from each bulked plot was ground to produce fine maize flour. Flour samples were stored at 
$-20{ }^{\circ} \mathrm{C}$ until the extraction of fumonisins and genomic DNA was performed.

\section{Quantification of Fusarium verticillioides in maize grain}

DNA was isolated from both fungal cultures $(0.02 \mathrm{~g})$ and milled maize samples (2.0 g), according to the methods described by Boutigny et al. (2012). Freezedried mycelia of MRC 826, GCI 315, GCI 790, the Kenyan isolates (UONK005, UONK038 and UONK048), as well as the maize samples were stored at $-20{ }^{\circ} \mathrm{C}$ until genomic DNA was extracted. Additional DNA extractions were performed on waterinoculated maize for use as target-DNA-free host DNA for the preparation of matrix matched standard curves. DNA was isolated using the commercially available DNeasy ${ }^{\circledR}$ Plant Mini kit (QIAGEN), with some modifications. The initial DNA isolation step consisted of the CTAB/PVP lysis method, and an additional phenol extraction step was performed on fungal cultures prior to the use of the commercial kit (Boutigny et al. 2012). The quantity and purity of the DNA yield of each fungal and grain sample was determined with a NanoDrop ND-1000 spectrophotometer (Inqaba Biotechnical Industries (Pty) Ltd., Pretoria, South Africa).

The fungal target DNA in maize samples was determined by qPCR according to Boutigny et al. (2012). The sensitivity of the qPCR primer pair to detect and quantify the isolates used in the South African and Kenyan trials was also confirmed prior to the analyses of maize samples. For direct comparisons with inoculated grain samples, a mixed DNA standard curve was prepared by diluting the $F$. verticillioides isolate MRC 826 DNA $\left(\sim 20 \mathrm{ng} \mu \mathrm{L}^{-1}\right) 4^{1}-4^{5}$-fold in water-inoculated maize DNA (10 ng $\mu \mathrm{L}^{-1}$ ). Real-time PCR reactions for each dilution were performed in triplicate and the standard curve was analysed using the RotorGeneTM 2.0.2.4 software (Corbett Life Science, Whitehead Scientific (Pty) Ltd., South Africa). It plotted the cycle threshold $\left(\mathrm{C}_{\mathrm{t}}\right)$ values of the diluted standards against the logarithm of the known DNA concentration (Nanodrop Spectrophotometer measurement). Dynamic tube normalisation, starting at Cycle 1 and noise slope correction for standard curve analysis was selected on the Rotor-GeneTM 2.0.2.4 software programme for all runs performed.
To assess the linearity and presence of inhibitors, the correlation coefficient $\left(\mathrm{R}^{2}\right)$, slope (M-value) and reaction efficiency (E-value) were noted after the analysis of the standard curve. Stringent parameters were set to ensure accurate, inhibition-free qPCR assays with $\mathrm{R}^{2}>0.99$, M-values of -3.4 , and an efficiency of 0.99 (Corbett Life Science 2006; European Commission 2008; Bustin et al. 2009). The melting temperature $\left(\mathrm{T}_{\mathrm{m}}\right)$ of $F$. verticillioides target DNA was evaluated to confirm analytical specificity in planta.

To quantify $F$. verticillioides target DNA in inoculated maize samples, the qPCR assays contained a duplicate of each sample and standard $F$. verticillioides DNA $\left(4^{2}, 4^{3}\right.$ and $4^{4}$-fold dilution of pathogen DNA in maize DNA free of $F$. verticillioides infection) were analysed in triplicate. All the assays contained a no template control (NTC). Using the matrix specific standard curves, the $\mathrm{C}_{t}$ values were transformed into DNA concentrations using the RotorGene $^{\mathrm{TM}}$ 2.0.2.4 software.

Fumonisin quantification from maize grain

Fumonisin levels in maize samples were determined by the dilute-and-shoot method using liquid chromatographic tandem mass spectrometry (LC-MS/ MS). Fumonisins were extracted from milled maize samples (5 g) according to Rose et al. (2016). The samples were diluted in a 1:1 ratio with HPLC-grade water and submitted to the Central Analytical Facility (CAF) at Stellenbosch University, South Africa for the detection and quantification of $\mathrm{FB}_{1}, \mathrm{FB}_{2}$ and $\mathrm{FB}_{3}$. $\mathrm{Fu}$ monisin standards $\left(\mathrm{B}_{1}[10 \mathrm{mg}], \mathrm{B}_{2}\right.$ [10 mg], and $\mathrm{B}_{3}$ [1 mg]), guaranteed $95 \%$ pure, were obtained from the Medical Research Council-Programme on Mycotoxins and Experimental Carcinogenesis (MRC-PROMEC), Tygerberg, South Africa. A dilution series that ranged between 0.05 and $20 \mathrm{mg} \mathrm{kg}^{-1}$ for $\mathrm{FB}_{1}$ and $\mathrm{FB}_{2}$, and between 0.005 and $2 \mathrm{mg} \mathrm{kg}^{-1}$ for $\mathrm{FB}_{3}$ was analysed with field trial samples. Each standard and sample $(5 \mu \mathrm{l})$ was injected into the LC-MS/MS system, and samples with results above of the calibration curve limit were appropriately diluted using HPLC-grade water and re-analysed. After adjustment for the volume of extract used in the purification procedure, the minimum limits of quantification for $\mathrm{FB}_{1}, \mathrm{FB}_{2}$ and $\mathrm{FB}_{3}$ were $0.02,0.002$ and $0.02 \mathrm{mg} \mathrm{kg}^{-1}$, respectively. 
Data analysis

The data obtained from the visual assessment of FER symptoms, fumonisin accumulation and $F$. verticillioides target DNA determination was subjected to univariate analysis of variance (ANOVA), employing the generalized linear model (GLM) procedure of SAS statistical software version 9.2 (SAS Institute Inc., Cary, NC, USA). The student's $t$ test, which determines least significant difference (LSD) between treatment means, was calculated at a 95\% confidence interval. Nonparametric Pearson correlation coefficients were determined to assess the relationships between FER symptoms, total fumonisin accumulated and fungal target DNA contamination using the CORR procedure in SAS employing the untransformed means of variables.

The data was furthermore subjected to additive main effects and multiplicative interaction (AMMI) analysis of variance (Gauch and Zobel 1996) using SAS statistical software version 9.2 (SAS Institute Inc., Cary, NC, USA). The genotype by environment $(\mathrm{G} \times \mathrm{E})$ interactions were partitioned amongst the first and second interaction principal components axes (IPCA) and the residual. The first principle component (PC1), located on the $X$-axis, indicates the level of resistance where inbred lines with higher PC1 values (positive or negative) are considered low risk to FER disease severity, $F$. verticillioides colonisation or fumonisin accumulation. The second principle component (PC2), located on the $Y$-axis, represents performance stability of genotypes where PC2 values near zero demonstrate greater adaptability of genotypes to different environments (Yan and Kang 2003).

The stability of the genotypes across locations was determined by the AMMI stability values (ASV) (Purchase et al. 2000), which is based on the first and second IPCA scores of the AMMI model for each genotype. The distance from a genotype's coordinate point to the origin in a two-dimensional scatter diagram determines the ASV value. Therefore, genotypes with the lowest ASV values exhibit the shortest projection from the biplot origin and are considered the most stable. Furthermore, the genotypic means relative to the principal components was graphically represented in GGE biplots. The GGE biplots were generated in GenStat 15th edition (Payne et al. 2012) by using the singular value decomposition (SVD) of the first two principle components (PC1 and PC2), according to Yan and Rajcan (2002). The GGE biplot graphically represented the genotype main effect and the $\mathrm{G} \times \mathrm{E}$ interaction (Yan 2001; Yan et al. 2000). The method is based on evaluating genotypes, firstly by considering only the effects of the genotype and $\mathrm{G} x \mathrm{E}$ as significant, while simultaneously taking these variables $(G+G E)$ into consideration. Secondly, it enabled the evaluation and representation of genotypes in different environments using the biplot technique (Gabriel 1971). Megaenvironments were determined on the "ideal genotype for a particular environment" or the "which-wonwhere" approach. This approach determined the best performing genotypes shared in the same environments consistently across years.

The estimation of resistance and stability of genotypes to FER, $F$. verticillioides colonisation and fumonisin accumulation was evaluated by an average environment coordination (AEC) method (Yan et al. 2000; Yan 2001; Yan and Rajcan 2002). It used the average principal components in all environments, represented as a circle, with a line drawn through the average environment and the biplot origin called the average environment axis (AEA). The perpendicular line passing through the AEA and the biplot origin, called the average ordinate environment (AEO), divided the genotypes into those exhibiting aboveaverage resistance (to the right of the AEO) and those showing below-average resistance (to the left of the AEO). Genotypes were projected on the AEA and ranked on resistance (low FER, F. verticillioides target DNA, fumonisins), with increased resistance in the direction of the arrow. The arrow points to a greater genotype main effect, while the AEC ordinate, and either direction away from the biplot origin, indicates greater $\mathrm{G} \times \mathrm{E}$ interaction effect and reduced stability.

The PC1 and PC2 were also used to obtain the ideal test environment, characterised by large PC1 scores (more power to discriminate genotypes in terms of the genotypic main effect) and small (absolute) PC2 scores (more representative of the overall environments) (Yan and Rajcan 2002). GGE biplots were constructed with genotype-focus and symmetrical scaling.

\section{Results}

Fusarium ear rot severity

Maize inbred lines evaluated in South Africa and Kenya differed significantly in their expression of FER 
Table 2 Mean Fusarium ear rot, Fusarium verticillioides colonisation and total fumonisin content of maize inbred lines evaluated in South Africa and Kenya during the 2012/2013 maize growing seasons

\begin{tabular}{|c|c|c|c|}
\hline Inbred line name & FER severity $(\%)^{1}$ & $\begin{array}{l}F . \text { verticillioides } \\
\text { colonisation }(\mathrm{ng} / \mathrm{uL})^{2}\end{array}$ & $\begin{array}{l}\text { Fumonisin accumulation } \\
\left(\mathrm{mg} / \mathrm{kg}^{-1}\right)^{3}\end{array}$ \\
\hline CB-222 & $10.2 b c$ & $0.031 \mathrm{~d}-\mathrm{h}$ & $3.2 \mathrm{c}-\mathrm{g}$ \\
\hline CB-248 & $6.3 \mathrm{~b}-\mathrm{g}$ & $0.038 \mathrm{~d}-\mathrm{f}$ & $3.8 \mathrm{~cd}$ \\
\hline CKL05003 & $6.3 \mathrm{~b}-\mathrm{g}$ & $0.024 \mathrm{e}-\mathrm{h}$ & $2.1 \mathrm{e}-\mathrm{g}$ \\
\hline CKL05015 & $3.3 \mathrm{fg}$ & $0.037 \mathrm{~d}-\mathrm{g}$ & $2.7 \mathrm{~d}-\mathrm{g}$ \\
\hline CKL05019 & $7.8 b-f$ & $0.019 \mathrm{f}-\mathrm{h}$ & $2.4 \mathrm{~d}-\mathrm{g}$ \\
\hline CKL05022 & $5.7 \mathrm{~b}-\mathrm{g}$ & $0.024 \mathrm{e}-\mathrm{h}$ & $2.2 \mathrm{e}-\mathrm{g}$ \\
\hline CML182 & $5.1 \mathrm{~d}-\mathrm{g}$ & $0.021 \mathrm{f}-\mathrm{h}$ & $2.8 \mathrm{~d}-\mathrm{g}$ \\
\hline CML247 & $6.0 \mathrm{~b}-\mathrm{g}$ & $0.066 b c$ & $3.4 \mathrm{c}-\mathrm{f}$ \\
\hline CML264 & $2.5 \mathrm{~g}$ & $0.024 \mathrm{e}-\mathrm{h}$ & $2.2 \mathrm{e}-\mathrm{g}$ \\
\hline CML390 & $5.7 \mathrm{~b}-\mathrm{g}$ & $0.036 \mathrm{~d}-\mathrm{g}$ & $2.6 \mathrm{~d}-\mathrm{g}$ \\
\hline CML444 & $9.4 b-d$ & $0.035 \mathrm{~d}-\mathrm{g}$ & $3.5 \mathrm{c}-\mathrm{e}$ \\
\hline CML495 & $2.0 \mathrm{~g}$ & $0.012 \mathrm{~h}$ & $2.0 \mathrm{fg}$ \\
\hline I137TNW & $19.0 \mathrm{a}$ & $0.039 \mathrm{~d}-\mathrm{f}$ & $4.3 \mathrm{bc}$ \\
\hline La Posta & $10.5 b$ & $0.019 \mathrm{f}-\mathrm{h}$ & $3.2 \mathrm{c}-\mathrm{g}$ \\
\hline MIRTC5 & $4.9 \mathrm{~d}-\mathrm{g}$ & $0.017 \mathrm{gh}$ & $2.1 \mathrm{e}-\mathrm{g}$ \\
\hline $\mathrm{P} 502 \mathrm{c} 2$ & $5.9 \mathrm{~b}-\mathrm{g}$ & $0.043 \mathrm{de}$ & $3.0 \mathrm{c}-\mathrm{g}$ \\
\hline R119 W & $20.8 \mathrm{a}$ & $0.139 a$ & $9.3 \mathrm{a}$ \\
\hline R2565y & $8.3 \mathrm{~b}-\mathrm{e}$ & $0.076 \mathrm{~b}$ & $5.6 \mathrm{~b}$ \\
\hline RO549W & $3.5 \mathrm{e}-\mathrm{g}$ & $0.017 \mathrm{gh}$ & $1.9 \mathrm{~g}$ \\
\hline US2540W & $5.4 \mathrm{c}-\mathrm{g}$ & $0.049 \mathrm{~cd}$ & $2.5 \mathrm{~d}-\mathrm{g}$ \\
\hline VO617y-2 & $2.7 \mathrm{~g}$ & $0.026 \mathrm{e}-\mathrm{h}$ & $4.2 \mathrm{bc}$ \\
\hline Mean & 7.2 & 0.038 & 3.3 \\
\hline
\end{tabular}

Means followed by the same alphabetical letter in each column are not significantly different according to the Student's t-test of least significant differences $(P \leq 0.05)$

1 The percentage of maize ears covered with visual symptoms of Fusarium ear rot

2 The absolute concentrations of $F$. verticillioides target DNA

3 Total fumonisin content as the sum of $\mathrm{FB}_{1}, \mathrm{FB}_{2}$ and $\mathrm{FB}_{3}$ for three field plots

symptoms. Lines designated as resistant accumulated $\leq 5.0 \%$ FER symptoms across localities and included Kenyan lines CML495 (2.0\%), CML264 (2.5\%), CKL05015 (3.3\%) and MIRTC5 Bco F78-2-2-1-11xDERRc2 15-3-7-1-1-B-B-B-B (MIRTC5; 4.9\%) as well as South African lines VO617y-2 (2.7\%) and RO549 W (3.5\%) (Table 2). FER symptoms were significantly $(\mathrm{P} \leq 0.05)$ influenced by the environment, genotype and the interactions between these factors (Table 3). The genotype $x$ environment interactions (GEI) was responsible for the largest variation and explained $57.9 \%$ of the variation observed, followed by the genotype $(25.0 \%)$ and environment $(17.1 \%)$ effect. The first and second interaction principle component axis (IPCA) were both significant, with IPCA1 accounting for $25.4 \%$ of the total $\mathrm{G} \times \mathrm{E}$ variation and IPCA2 for $17.1 \%$ of the variation observed (Table 3 ). In total, the two PCA's accounted for $42.5 \%$ of the variability in FER disease symptom expression. Stability of inbred line's response varied across locations, with ASV ranging from 0.35 to 1.69 , and a mean of 0.82 (Table 4). Inbred lines CML264 (0.35), MIRTC5 (0.45), CML495 (0.46), P502c2-185-3-4-2-3-B-2-B-B-B-BB-B (P502c2; 0.48), CKL05003 (0.52), VO617y-2 (0.53), La Posta Seq C7-F103-2-1-1-1xMIRTC5 Bco F80-4-2-1-1-1-3-1-B-B-B (La Posta; 0.54), US2540 W (0.61), CML390 (0.68) and I137tnW (0.69) were the most stable in their response to FER across locations. Conversely, inbred lines CML444 


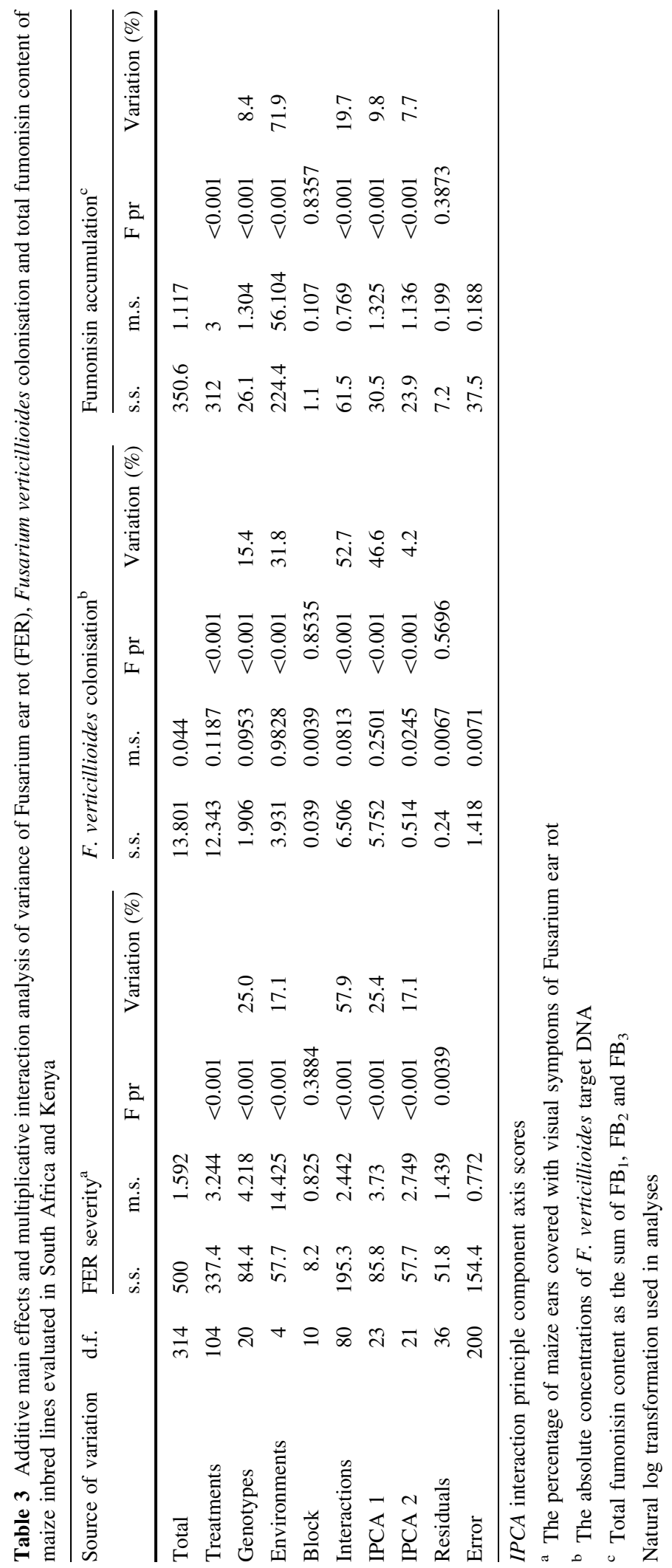


Table 4 Additive main effects and multiplicative interaction analysis stability values (ASVs) and interaction principle component axes (IPCA) values for Fusarium ear rot (FER),
Fusarium verticillioides colonisation and total fumonisin content of maize inbred lines evaluated in South Africa and Kenya

\begin{tabular}{|c|c|c|c|c|c|c|c|c|c|}
\hline \multirow[t]{2}{*}{ Inbred line name } & \multicolumn{3}{|c|}{ FER severity $^{\mathrm{a}}$} & \multicolumn{3}{|c|}{ F. verticillioides colonisation ${ }^{\mathrm{b}}$} & \multicolumn{3}{|c|}{ Fumonisin accumulation $^{\mathrm{c}}$} \\
\hline & IPCA1 & IPCA2 & ASV & IPCA1 & IPCA2 & ASV & IPCA1 & IPCA2 & ASV \\
\hline CB-222 & 0.6 & -0.54 & 1.04 & 0.05 & -0.22 & 0.58 & -0.38 & -0.18 & 0.51 \\
\hline CB-248 & 0.71 & 0.21 & 1.08 & -0.11 & -0.12 & 1.19 & -0.37 & 0.23 & 0.53 \\
\hline CKL05003 & 0.3 & 0.27 & 0.52 & 0.15 & -0.03 & 1.64 & -0.1 & -0.19 & 0.23 \\
\hline CKL05015 & 0.01 & -1.12 & 1.12 & 0.17 & -0.13 & 1.86 & -0.48 & -0.47 & 0.77 \\
\hline CKL05019 & -0.85 & -0.18 & 1.27 & -0.02 & 0.14 & 0.25 & 0.35 & -0.12 & 0.46 \\
\hline CKL05022 & -0.69 & 0.03 & 1.02 & 0.02 & 0.14 & 0.26 & 0.25 & 0.05 & 0.32 \\
\hline CML182 & 0.58 & 0.03 & 0.87 & 0.13 & 0 & 1.41 & -0.43 & -0.64 & 0.84 \\
\hline CML247 & -0.55 & -0.05 & 0.83 & 0.17 & 0.13 & 1.88 & 0 & -0.48 & 0.48 \\
\hline CML264 & -0.19 & 0.21 & 0.35 & -0.04 & 0.1 & 0.45 & 0.18 & 0.22 & 0.32 \\
\hline CML390 & 0.12 & -0.66 & 0.68 & 0.17 & -0.19 & 1.87 & -0.27 & -0.15 & 0.37 \\
\hline CML444 & -1.14 & 0.06 & 1.69 & 0.19 & 0.29 & 2.1 & 0.89 & -0.73 & 1.35 \\
\hline CML495 & -0.31 & -0.09 & 0.46 & 0.12 & 0.07 & 1.37 & -0.15 & -0.18 & 0.26 \\
\hline I137TNW & 0.18 & 0.63 & 0.69 & -1.06 & 0.04 & 11.88 & 0.21 & 0.7 & 0.75 \\
\hline La Posta & 0.31 & -0.27 & 0.54 & 0.06 & 0.04 & 0.63 & 0.13 & 0.17 & 0.24 \\
\hline MIRTC5 & -0.22 & 0.31 & 0.45 & 0.08 & 0.1 & 0.86 & 0.17 & 0.11 & 0.24 \\
\hline P502c2 & -0.26 & 0.29 & 0.48 & -0.01 & 0.1 & 0.18 & 0.8 & 0.36 & 1.08 \\
\hline R119 W & 0.23 & 0.86 & 0.92 & -0.19 & -0.12 & 2.16 & -0.41 & 0.29 & 0.6 \\
\hline $\mathrm{R} 2565 \mathrm{Y}$ & 0.6 & -0.24 & 0.92 & -0.06 & -0.08 & 0.72 & -0.59 & 0.56 & 0.94 \\
\hline RO549W & 0.66 & 0.38 & 1.05 & 0.01 & 0.02 & 0.13 & 0.29 & 0.05 & 0.38 \\
\hline US2540W & 0.05 & -0.6 & 0.61 & 0.09 & -0.32 & 1.07 & -0.21 & 0.03 & 0.27 \\
\hline VO617y-2 & -0.15 & 0.48 & 0.53 & 0.11 & 0.04 & 1.22 & 0.11 & 0.35 & 0.38 \\
\hline Mean & & & 0.82 & & & 1.61 & & & 0.54 \\
\hline
\end{tabular}

a The percentage of maize ears covered with visual symptoms of Fusarium ear rot

b The absolute concentrations of $F$. verticillioides target DNA

c Total fumonisin content as the sum of $\mathrm{FB}_{1}, \mathrm{FB}_{2}$ and $\mathrm{FB}_{3}$ for three field plots

(1.69), CKL050019 (1.27), CKL050015 (1.12), CB248 (1.08), RO549 W (1.05), CB-222 (1.04) and CKL05022 (1.02) were least stable in their expression of FER symptoms across locations (Table 4).

The genotype main effect and GEI was visualised by GGE biplot analysis (Fig. 1). In this study, the first two principal components accounted for $72.6 \%$ $(\mathrm{PC} 1=47.2 \%$ and $\mathrm{PC} 2=25.4 \%)$ of the total GGE variation for FER severity (Fig. 1). The genotyperanking biplot revealed CML495 (\#12), CML264 (\#9) and VO 617y-e (\#21) as the most resistant to FER, with CML495 (\#12) being the most stable (Fig. 1a). The genotype-comparison biplot supported this result, with CML495 (\#12) being found the ideal genotype with the lowest FER severity and greatest stability across localities (Fig. 1b). Inbred lines CKL05015 (\#4), CML264 (\#9) and US2540 W (\#20) were also identified as ideal genotypes, based on their proximity to CML495. Lines I137tnW (\#13) and R119 W (\#17) were the most susceptible genotypes (Fig. 1a, b). The polygon view, displaying the "which-won-where" pattern of the GGE biplot, revealed that inbred line CKL05015 (\#4) was most resistant to FER at Makhatini, Potchefstroom and Kiboko, resulting in a megaenvironment (Fig. 1c). Inbred lines US2540 W (\#20) and CML390 (\#10) were also resistant to FER. Inbred CML444 (\#11) was most resistant to FER at Katumani, while CB-222 (\#1) was most resistant in Vaalharts. Inbred lines CKL05015 (\#4), CML444 (\#11), R119 W (\#17) and CB-222 (\#1) served as 

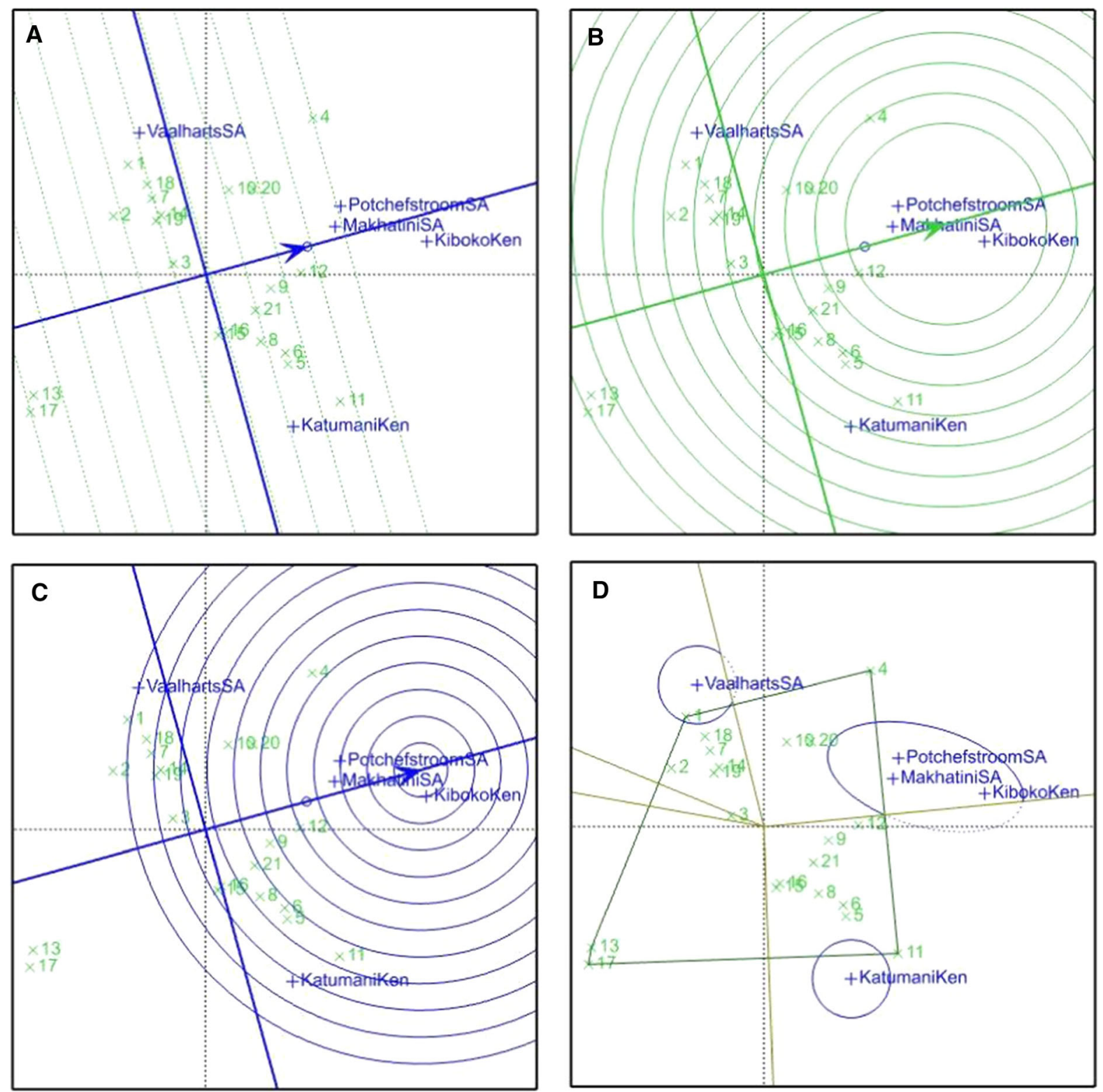

Fig. 1 Genotype main effect and genotype by environment interaction biplot for Fusarium ear rot severity in 21 maize inbred lines tested, based on environment-focused scaling for a the genotype ranking, $\mathbf{b}$ genotype comparison, $\mathbf{c}$ environment comparison and $\mathbf{d}$ the polygon view exhibiting mega-

vertex hybrids forming the polygon, and were the most affected by GEI due to their distance from the biplot origin. The high PC1 value and low PC2 score of the environment comparison biplot revealed Kiboko as the ideal test environment, followed by Potchefstroom and Makhatini (Fig. 1d).

environments. Green and blue numbers represent genotypes and environments, respectively, with localities represented as: Potchefstroom (SA), Makhatini (SA), Kiboko (KEN) and Katumani (KEN). (Color figure online)

\section{Fusarium verticillioides colonisation}

Grain colonisation by $F$. verticillioides, as determined by the quantity of fungal target DNA, differed significantly in maize inbred lines across localities (Table 2). Resistant lines accumulated $\leq 0.025 \mathrm{ng} \mu \mathrm{L}^{-1}$ fungal 
target DNA and included Kenyan lines CML495 (0.012 ng $\mu \mathrm{L}^{-1}$ ), MIRTC5 (0.017 ng $\left.\mu \mathrm{L}^{-1}\right)$, La Posta and CKL05019 (0.017 $\left.\mathrm{ng} \mu \mathrm{L}^{-1}\right)$ as well as CKL05003, CKL05022 and CML264 (0.024 ng $\left.\mu \mathrm{L}^{-1}\right)$. South

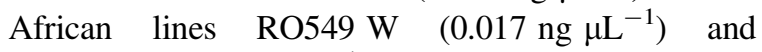
CML182 (0.021 ng $\mu \mathrm{L}^{-1}$ ) were also resistant to fungal colonisation across localities (Table 2). The fungal DNA was significantly $(\mathrm{P} \leq 0.05)$ influenced by the inbred line (genotype), locality (environment) and the interaction between the two (Table 3). The $\mathrm{G} \times \mathrm{E}$ interaction was responsible for $52.7 \%$ of the variation, while the environment and genotype accounted for 31.8 and $15.4 \%$ of the variation, respectively. Further analysis of the GEI revealed that IPCA 1 and IPCA2 were both significant and explained 46.6 and $4.2 \%$ of the variation observed, respectively. In total the IPCAs accounted for $50.8 \%$ of the total $\mathrm{G} \times \mathrm{E}$ variation influencing fungal colonisation. The stability of inbred line response to $F$. verticillioides colonisation, as determined by the ASV, ranged between 0.13 and 11.88 with a mean of 1.61 (Table 4). Inbred line RO549 W (0.13), P502c2 (0.18), CKL05019 (0.25), CKL05022 (0.26) and CML264 (0.45) were the most stable in their response to fungal colonisation across localities, while I137tnW (11.88) was the least stable (Table 4).

The first two principal components of the GGE biplot analysis accounted for $95.2 \%$ (PC1: $87.2 \%$ and PC2: $8.0 \%$ ) of the total GGE variation for fungal colonisation (Fig. 2). Genotype ranking and genotype comparison biplots were congruent in determining CML495 (\#12), CKL05019 (\#5) and CML444 (\#11) as ideal genotypes with stable resistance to fungal colonisation across localities, while I137tnW (\#13) was the worst performing genotype (Fig. 2a, b). Inbred line CML444 (\#11) was the best performing genotype across all environments, resulting in all the localities constituting a single mega-environment (Fig. 2c). Other inbred lines that were also resistant across localities included CML495 (\#12), CKL05019 (\#5), CML264 (\#9) and CML247 (\#8) and CKL05022 (\#6). Vertex genotypes CML444 (\#11), CKL05015 (\#4), US2540 W (\#20) and I137tnW (\#13) delimited the polygon and differed most in their response to fungal colonisation (Fig. 2c). Environment-comparison biplot revealed Kiboko as the ideal test environment, followed by Katumani, Makhatini and Potchefstroom (Fig. 2d).
Fumonisin accumulation

Maize inbred lines accumulated significantly different levels of fumonisins across localities. Kenyan lines CML495 (2.0 mg kg${ }^{-1}$ ), MIRTC5 and CKL05003 (2.1 $\left.\mathrm{mg} \mathrm{kg}^{-1}\right)$, CKL05022 and CML264 (2.2 $\mathrm{mg} \mathrm{kg}^{-1}$ ) and CKL05019 (2.4 mg kg-1) was considered highly resistant to fumonisin accumulation. South African lines RO549 W (1.9 mg kg-1) and US2540 W (2.5 mg kg $\left.{ }^{-1}\right)$ were also highly resistant to fumonisin accumulation (Table 2). The environment, genotype and the interaction between them $(\mathrm{P} \leq 0.05)$ had a highly significant effect on the total fumonisins that accumulated in the grain of maize inbred lines (Table 3). The largest source of variation in fumonisin contamination was the environment, and it explained $71.9 \%$ of the total variation. The genotype and GEI further accounted for 8.4 and $19.7 \%$ of the variation, respectively. The IPCA1 and IPCA 2 were both significant and explained 9.8 and $7.7 \%$ of the total variation, respectively (Table 3 ). The stability of inbred line response to fumonisin accumulation across environments was determined by ASV, which ranged from 0.23 to 1.35 (Table 4). Inbred line CKL05003 (0.23), La Posta (0.24), MIRTC5 (0.24), CML495 (0.26), US2540 W (0.27), CKL05022 (0.32) and CML264 (0.32) were most stable in their response to fumonisin accumulation across localities, while CML444 (1.35) and P502c2 (1.08) were the least stable (Table 4).

The principal components of the GEI affecting fumonisin accumulation accounted for $79.8 \%$ (PC1: $45.1 \%$ and $\mathrm{PC} 2: 34.7 \%$ ) of the total GGE variation (Fig. 3a). Inbred line CML247 (\#8) was the most resistant to fumonisin accumulation, along with CKL05003 (\#3) and CML495 (\#12). The ideal genotype based on mean and stability in the genotypecomparison biplot revealed CML247 (\#8) as the ideal genotype, while CKL05003 (\#3) and CML495 (\#12) were desirable due to their proximity to CML247 (Fig. 3b). The inbred lines CML444 (\#11), CKL05015 (\#4), R2565y (\#18), R119 W (\#17), I137tnW (\#13) and P502c2 (\#16) formed the polygon and differed most in their response to fumonisin contamination (Fig. 3c). Line CML444 (\#11) was the best performing genotype at Katumani, Makhatini and Potchefstroom, which resulted in a mega-environment for this inbred line. Line CKL05015 (\#4) was the best 

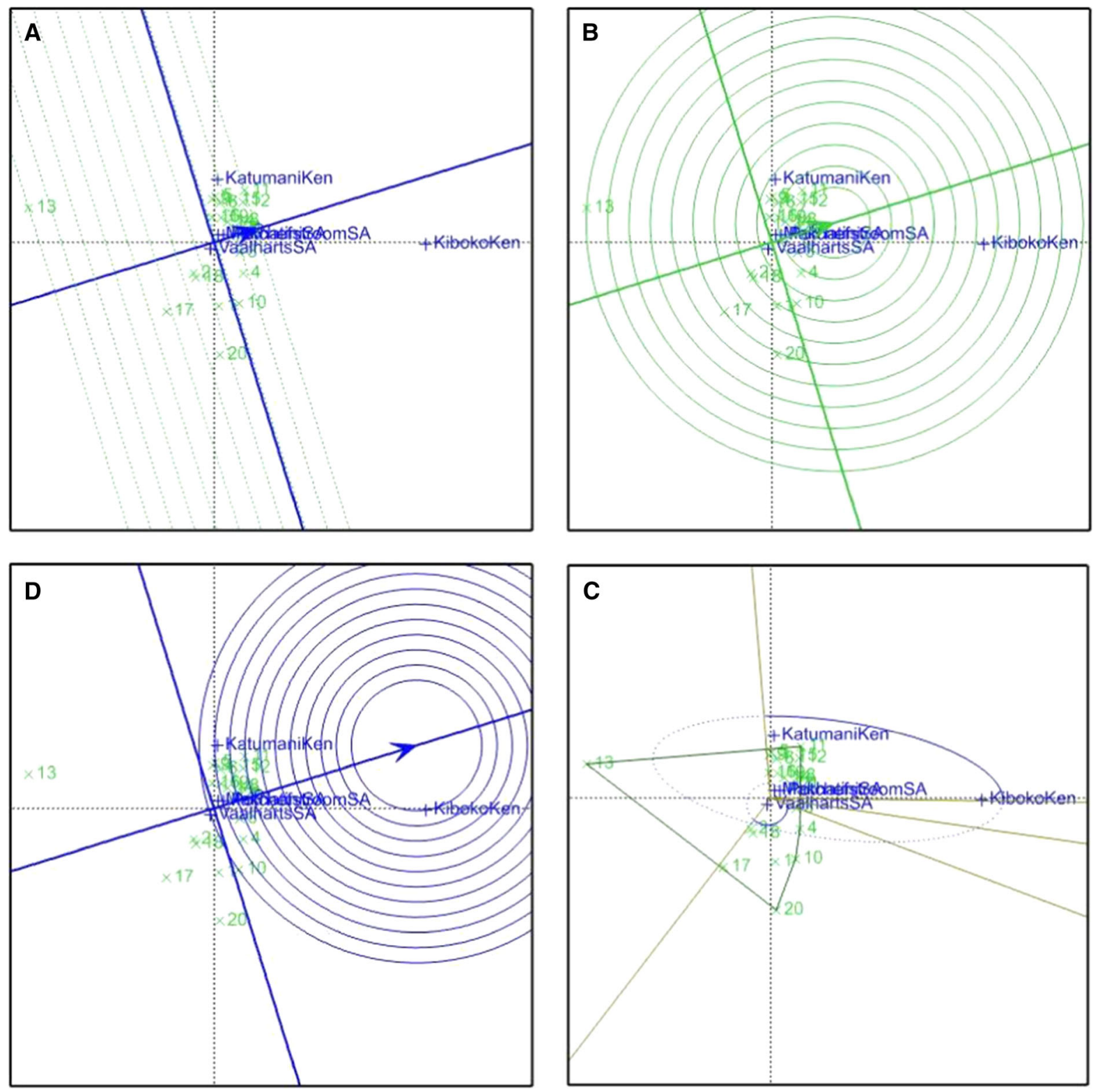

Fig. 2 Genotype main effect and genotype by environment interaction biplot for Fusarium verticillioides colonisation in 21 maize inbred lines tested, based on environment-focused scaling for a the genotype ranking, b genotype comparison, $\mathbf{c}$ environment comparison and $\mathbf{d}$ the polygon view exhibiting mega-

performing genotype at Kiboko, while R2565y (\#18) was the best performing genotype at Vaalharts. The localities evaluated were divided into different sectors, indicating significant crossover interaction, with Kiboko being the ideal test environment (Fig. 3d).

environments. Green and blue numbers represent genotypes and environments, respectively, with localities represented as: Potchefstroom (SA), Makhatini (SA), Kiboko (KEN) and Katumani (KEN). (Color figure online)

Correlations between FER symptoms, Fusarium verticillioides target DNA and total fumonisins

Significant correlations were obtained between FER severity, fungal colonisation and total fumonisin 

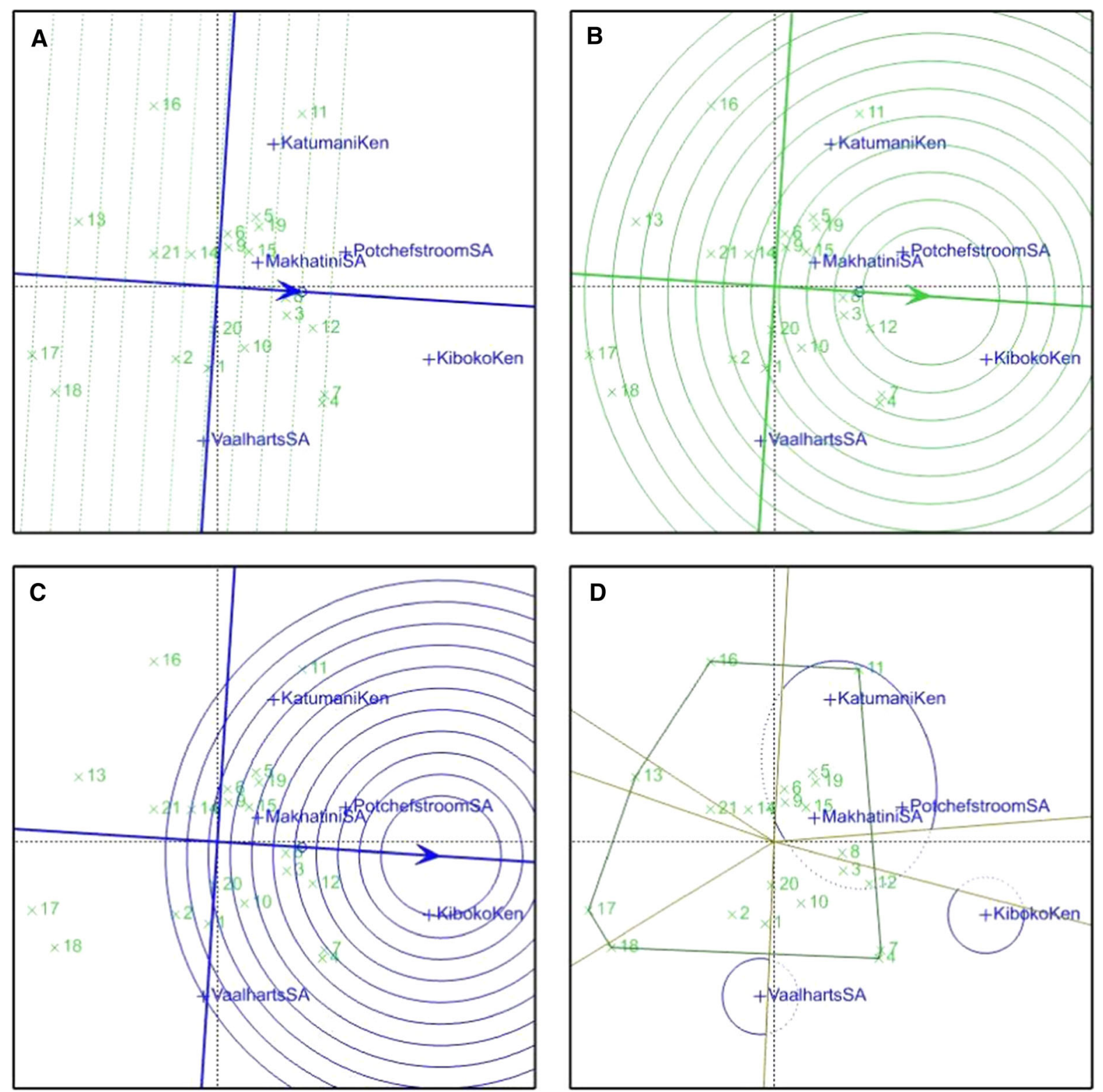

Fig. 3 Genotype main effect and genotype by environment interaction biplot for total fumonisin accumulation in 21 maize inbred lines tested, based on environment-focused scaling for $\mathbf{a}$ the genotype ranking, $\mathbf{b}$ genotype comparison, $\mathbf{c}$ environment comparison and $\mathbf{d}$ the polygon view exhibiting mega-

content at all the test localities (Table 5). Disease severity had a significant but moderate correlation with $F$. verticillioides target DNA $(R=0.54$; $\mathrm{P}<0.0001)$, and a significant yet weak relationship with total fumonisins $(R=0.38 ; \mathrm{P}=0.0019)$ at Makhatini. Fungal target DNA and fumonisins showed a significant, strong correlation $(R=0.66$;

environments. Green and blue numbers represent genotypes and environments, respectively, with localities represented as: Potchefstroom (SA), Makhatini (SA), Kiboko (KEN) and Katumani (KEN). (Color figure online)

$\mathrm{P}<0.0001)$. At Potchefstroom, a significant but moderate correlation was found between FER severity and fungal target DNA $(R=0.58 ; \mathrm{P}<0.0001)$, while a significant, strong correlation was obtained between disease severity and total fumonisins $(R=0.88$; $\mathrm{P}<0.0001)$, as well as between fungal target DNA content and total fumonisin content $(R=0.76$; 
Table 5 Correlations between Fusarium ear rot severity, Fusarium verticillioides colonisation and total fumonisin content at field localities in South Africa and Kenya

\begin{tabular}{lllll}
\hline Locality & Country & FER/F. verticillioides DNA & FER/Fumonisins & $\begin{array}{l}\text { F. verticillioides } \\
\text { DNA/Fumonisins }\end{array}$ \\
\hline Makhatini & South Africa & $0.54^{*}$ & $0.38 \mathrm{P}=0.0019$ & 0.66 \\
Potchefstroom & South Africa & $0.58^{*}$ & $0.88^{*}$ & 0.76 \\
Vaalharts & South Africa & $0.82^{*}$ & $0.77^{*}$ & 0.81 \\
Katumani & Kenya & $0.40 \mathrm{P}=0.0011$ & $0.39 \mathrm{P}=0.0015$ & 0.55 \\
Kiboko & Kenya & $0.56^{*}$ & $0.55^{*}$ & 0.58 \\
Combined & - & 0.63 & 0.63 & 0.67 \\
\hline
\end{tabular}

F. verticillioides DNA - fungal target DNA indicative of grain colonisation

Fumonisins - total fumonisins $\left(\mathrm{FB}_{1}+\mathrm{FB}_{2}+\mathrm{FB}_{3}\right)$

FER fusarium ear rot

$* \mathrm{P}<0.0001$

$\mathrm{P}<0.0001$ ). Significant, strong relationships were found at Vaalharts between FER severity and $F$. verticillioides target DNA $(R=0.82 ; \mathrm{P}<0.0001)$, disease severity and total fumonisin content ( $R=0.77 ; \mathrm{P}<0.0001$ ), as well as between fungal target DNA and total fumonisins $(R=0.81$; $\mathrm{P}<0.0001$ ) (Table 5).

FER severity at Katumani had a significant though moderate correlation with fungal target DNA content $(R=0.40 ; \mathrm{P}=0.0011)$ and total fumonisin content $(R=0.39 ; \mathrm{P}=0.0015)$ (Table 5). The $F$. verticillioides content of inbred lines also had a significant but moderate correlation with total fumonisin content $(R=0.55 ; \mathrm{P}<0.0001)$. At Kiboko, significant but moderate relationships were obtained between FER severity and fungal target DNA $(R=0.56$; $\mathrm{P}<0.0001)$, disease severity and total fumonisin content $(R=0.55 ; \mathrm{P}<0.0001)$ and fungal target DNA content and total fumonisins $(R=0.58$; $\mathrm{P}<0.0001)$. Across all localities, significant, strong correlations were found between FER severity and $F$. verticillioides target DNA $(R=0.63 ; \mathrm{P}<0.0001)$, disease severity and total fumonisin content ( $R=0.63 ; \mathrm{P}<0.0001$ ), as well as between fungal target DNA content and total fumonisins $(R=0.67$; $\mathrm{P}<0.0001$ ) (Table 5).

\section{Discussion}

This study investigated Kenyan maize inbred lines, previously characterised for resistance to A. flavus and aflatoxin contamination, for $F$. verticillioides resistance for the first time, both under South African and Kenyan conditions. The Kenyan maize inbred line CML495 was found to be more resistant to FER, $F$. verticillioides colonisation and fumonisin accumulation across environments than any of the South African inbred lines previously characterised in South Africa. The inbred line's performance was stable across locations, even when evaluated under temperate conditions when compared to its adapted tropical and subtropical conditions. Therefore, CML495 is also considered to have broad adaptability. It has also been characterised as a late maturing line (CIMMYT 2005), which dries down slower than early maturing lines, thereby potentially extending the conditions conducive for fumonisin deposition. Nonetheless, CML495 demonstrated superior resistance to $F$. verticillioides infection and fumonisins. The maturity class of hybrids had the greatest effect on fumonisin contamination in a study in northern Italy (Battilani et al. 2008) while other studies noted that the maturity class did not influence the final fumonisin concentration in maize kernels (Ramirez et al. 1996; Blandino et al. 2009; Battilani et al. 2011). Hybrids with the slowest kernel drying rate, however, were most favourable for fumonisin accumulation irrespective of the maturity classification (Battilani et al. 2011). The use of CML495 in breeding programmes would not only provide a source of resistance to $A$. flavus and aflatoxins, but provide comprehensive resistance to $F$. verticillioides and fumonisin contamination too. 
Two additional Kenyan inbred lines, CML264 and CKL05015, also developed less than 5\% FER, with grain containing less than $0.025 \mathrm{ng} \mu \mathrm{L}^{-1}$ fungal target DNA and less than $2.5 \mathrm{mg} \mathrm{kg}^{-1}$ fumonisins. Inbred line CML264 was more stable in its response to disease expression, fungal colonisation and fumonisin accumulation. Inbred line CKL05015 was less stable in its response to FER severity across localities and showed specific adaptation at localities like Kiboko and Vaalharts where it showed resistance to fungal and fumonisin contamination. Inbred lines resistant to AER and aflatoxin accumulation, thus, appeared to be good sources of resistance to $F$. verticillioides and fumonisin accumulation. The identification of new sources of resistance to FER and fumonisin accumulation is of great importance, as all cultivars grown in South Africa are highly susceptible to FER and fumonisin contamination, with fumonisin levels often exceeding the tolerable limits enforced in Europe and the USA (Rheeder et al. 1990; Janse van Rensburg et al. 2015).

The response of inbred lines to FER, F. verticillioides colonisation and total fumonisin content was not always congruent. Inbred lines CKL05019, La Posta, CB-222 and CML444; which were all highly susceptible to FER, were intermediately resistant to fungal colonisation and fumonisins contamination. Inbred line CML247, which was intermediately resistant to FER, was susceptible to fungal colonisation but accumulated low levels of fumonisins. These results suggest that the genetic potential for resistance to FER (disease expression), fungal colonisation and fumonisin accumulation may exist independently from one another and is predominantly determined by the genetic composition of the maize line and the environment.

GEI significantly affected the performance of all inbred lines evaluated in this study. The GEI contributed more to the variation in FER severity and fungal colonisation than the genotype or environment, while the environment contributed the most to the variation observed in fumonisin content. These results indicate that inbred line response to $F$. verticillioides infection is dependent on the plant genotype to resist or succumb to infection under prevailing environmental conditions that support fungal development, inoculum pressure and insect infestation (Munkvold 2003).

The significant influence of the environment on fumonisin accumulation indicates the need to determine the suitability of an environment to promote the biosynthesis of fumonisins by $F$. verticillioides. Differential response of inbred lines to FER and fumonisin accumulation due to GEI has previously been documented (Clements and White 2004; Afolabi et al. 2007; Small et al. 2012; Rose et al. 2016), while fumonisin contamination was shown to be predominantly affected by the prevailing environmental conditions (Cao et al. 2014). This was also observed by de la Campa et al. (2005) when modelling the effects of environment, insect damage and $B t$ genotypes on fumonisin accumulation. The strong influence of environment on fumonisin accumulation accentuates the value of evaluating resistance to fumonisin accumulation in target environments. Fumonisin accumulation of maize inbred lines was particularly severe in Kiboko, Kenya. The contamination levels of maize grain obtained in this location far exceeded the $4 \mathrm{mg} \mathrm{kg}^{-1}$ fumonisin allowed for human and animal consumption as set by United States authorities (FDA 2000). The region is characterised by a bimodial rainfall with long rains occurring in March to May and short rains occurring from October to December/ January. In 2013 the mean rainfall of 107.5 and $54.5 \mathrm{~mm}$ recorded at Kiboko during the long and short rainfall period, respectively, differed significantly from Katumani. The rainfall coincided with the grain filling period, while mean maximum temperature at Kiboko $\left(31.3{ }^{\circ} \mathrm{C}\right)$ also differed significantly from Katumani $\left(25.5{ }^{\circ} \mathrm{C}\right)$, creating a favourable environment for fumonisin production at Kiboko (Janse van Rensburg 2011). Temperature was shown to play a significant role in fumonisin production during the dough-stage of grain fill (de la Campa et al. 2005; Janse van Rensburg 2011) while drought-stress significantly affected FER and fumonisins (Parsons and Munkvold 2010). Kiboko provides the ideal environment for evaluating maize genotypes for resistance to $F$. verticillioides and more specifically fumonisin accumulation.

Significant, though inconsistent relationships between FER, $F$. verticillioides target DNA and total fumonisin content were obtained in this study. Significantly moderate correlations were obtained between FER and fungal target DNA at all localities except Vaalharts where a strong, positive correlation was obtained. Poor to moderate correlations were obtained between FER and fumonisin content at Makhatini, Katumani and Kiboko while strong, 
positive correlations were obtained at Potchefstroom and Vaalharts. The relationship between fungal and fumonisin contamination was moderate to strong at all the localities. These results demonstrate the inconsistency of the relationship between FER/fungal target DNA and FER/fumonisins in selecting for reduced fumonisins, as they were significantly influenced by the production season (prevailing weather conditions and trial management practises). The relationship between fungal target DNA and fumonisins provided a more accurate indication of potential resistance to fumonisin accumulation (Janse van Rensburg et al. 2015; Rose et al. 2016). The inbred lines CKL05019, CB-222, La Posta and CML444 were highly susceptible to FER, with little fumonisin contamination, which reduced the relationship between these variables. These results emphasize the need for fumonisin analysis when evaluating resistance to FER and fumonisins (Afolabi et al. 2007; Small et al. 2012; Rose et al. 2016). The reduced relationship between FER severity, $F$. verticillioides and fumonisins could also be due to inaccurate visual assessment of disease symptoms and the ability of other Fusarium species to cause maize ear rot diseases. The cost and expertise required to quantify fungal target DNA or fumonisins may, however, be a deterrent in their implementation in resistance breeding programmes.

The use of resistant cultivars is considered the most economically viable, environmentally sound and convenient for producers to manage fumonisin contamination (Clements and White 2004). In this study, inbred lines resistant to AER and aflatoxin accumulation were more resistant to FER and fumonisin accumulation across localities when compared to South African FER/fumonisin-resistant inbred lines. These lines provide additional sources of resistance that could be used to improve resistance to FER and fumonisin in elite local lines or be used for the development of hybrids with improved resistance. The inbred lines are also a valuable resource that could be utilised in genomic and proteomic approaches to understand resistance mechanisms toward AER, FER and their associated mycotoxins.

Acknowledgements The MAIZE Competitive Grants Initiative, International Maize and Wheat Improvement Centre (CIMMYT) and CGIAR, South African Maize Trust and the South African National Research Foundation (NRF): Technology and Human Resources for Industry Programme (THRIP) of South Africa are acknowledged for funding of this research. We also thank Dr. K. Mashingaidze from the Agricultural Research Council-Grain Crops Institute (ARCGCI), South Africa for providing the inbred line seed; Drs Schoeman and Janse van Rensburg (ARC-GCI) for fungal isolates; Dr. H. Vismer from the Medical Research CouncilProgramme on Mycotoxins and Experimental Carcinogenesis unit, South Africa for providing the fungal isolate MRC 826 and Drs M. van der Rijst and M. Booyse from ARC-Infruitec for statistical analyses.

\section{References}

Abbas HK, Cartwright RD, Xie W, Shier WT (2006) Aflatoxin and fumonisin contamination of corn (maize, Zea mays) hybrids in Arkansas. Crop Prot 25:1-9

Afolabi CG, Ojiambo PS, Ekpo EJA, Menkir A, Bandyopadhyay R (2007) Evaluation of maize inbred lines for resistance to Fusarium ear rot and fumonisin accumulation in grain in tropical Africa. Plant Dis 91:279-286

Battilani P, Pietri A, Barbano C, Scandolara A, Bertuzzi T, Marocco A (2008) Logistic regression modeling of cropping systems to predict fumonisin contamination in maize. J Agric Food Chem 56:10433-10438

Battilani P, Formenti S, Ramponi C, Rossi V (2011) Dynamic of water activity in maize hybrids is crucial for fumonisin contamination in kernels. J Cereal Sci 54:467-472

Blandino M, Reyneri A, Vanara F (2009) Effect of sowing time on toxigenic fungal infection and mycotoxin contamination of maize kernels. J Phytopathol 157:7-14

Booth C (1971) The genus Fusarium. Commonwealth Mycological Institute, Kew, p 237

Boutigny A-L, Beukes I, Small I, Zühlke S, Spiteller M, Van Rensburg BJ, Flett B, Viljoen A (2012) Quantitative detection of Fusarium pathogens and their mycotoxins in South Africa. Plant Pathol 61:522-531

Bustin SA, Benes V, Garson JA, Hellemans J, Huggett J, Kubista M, Mueller R, Nolan T, Pfaffl MW, Shipley GL, Vandesompele J, Wittwer CT (2009) The MIQE guidelines: minimum information for publication of quantitative real-time PCR experiments. Clin Chem 55:611-622

Cao A, Butron A, Ramos AJ, Marin S, Souto C, Santiago R (2014) Assessing white maize resistance to fumonisin contamination. Eur J Plant Pathol 138:283-292

CIMMYT (2005) Maize inbred lines released by CIMMYT. A compilation of CIMMYT maize lines (CMLs). http:// libcatalog.cimmyt.org/download/cim/96840.pdf. Accessed 03 March 2016

Clements MJ, White DG (2004) Identifying sources of resistance to aflatoxin and fumonisin contamination in corn grain. J. Toxicol. 23:381-396

Colvin BM, Harrison LR (1992) Fumonisin-induced pulmonary edema and hydrothorax in swine. Mycopathologia 117:79-82

Corbett Life Science (2006) Rotor-GeneTM 6000 operator manual. Corbett robotics, Queensland, Australia, p 152

De la Campa R, Hooker DC, Miller JD, Schaafsma AW, Hammond BG (2005) Modeling effects of environment, insect damage, and $\mathrm{Bt}$ genotypes on fumonisin 
accumulation in maize in Argentina and the Philippines. Mycopathologia 159:539-552

Eller MS, Payne GA, Holland JB (2010) Selection for reduced Fusarium ear rot and fumonisin content in advanced backcross maize lines and their topcross hybrids. Crop Sci 50:2249-2260

European Commission (2007) Commission Regulation (EC) No $1126 / 2007$ of 26 September 2007 amending regulation (EC) No 1881/2006 setting maximum levels for certain contaminants in foodstuffs as regards Fusarium toxins in maize and maize products. Off $\mathbf{J}$ Eur Union Legis 254:14-17

European Commission: Institute for Health and Consumer Protection (2008) Report of the verification of the performance of a method for the detection of DAS-59132-8 (Event 32) in maize using real-time PCR. CRL-EM-01/08. Ispra, Italy. Community reference laboratory for GM food and feed. http://gmocrl.jrc.ec.europa.eu/doc/Maize_E32_ verification_report.pdf. Accessed 23 January 2015

Fandohan P, Gnonlonfin B, Hell K, Marasas WFO, Wingfield MJ (2005) Natural occurrence of Fusarium and subsequent fumonisin contamination in preharvest and stored maize in Benin, West Africa. Int J Food Microbiol 99:173-183

FDA (Food and Drug Administration) (2000) Guidance for industry: action levels for poisonous or deleterious substances in human food and animal feed. http://www.fda. gov/food/guidanceregulation/ucm077969.htm. Accessed 20 Nov 2015

Franceshi S, Bidoli E, Baron AE, La Veccbia C (1990) Maize and risk of cancers of the oral cavity, pharynx and esophagus in Northern Italy. J Natl Cancer Inst 82:1407-1411

Gabriel KR (1971) The biplot graphic display of matrices with application to principal component analysis. Biometrics 58:453-467

Gauch HG, Zobel RW (1996) AMMI analysis of yield trials. In: Kang MS, Gauche HG (eds) Genotype by environment interaction. CRC Press, Boca Raton, pp 85-122

Giorni P, Battilani P, Magan N (2009) Effect of solute and matric potential on in vitro growth and sporulation of strains from a new population of Aspergillus flavus isolated in Italy. Fungal Ecol 1:101-106

Gong YY, Cardwell K, Hounsa A, Egal S, Turner PC, Hall AJ, Wild CP (2002) Dietary aflatoxin exposure and impaired growth in young children from Benin and Togo: cross sectional study. BMJ 325:20-21

Government Gazette (2004) Foodstuffs, cosmetics and disinfectant Act, 1972 (Act no. 54 of 1972). No. 26849: 7

Government Gazette (2016) Foodstuffs, cosmetics and disinfectant Act, 1972 (Act no. 54 of 1972). No. 26849: 7 (Amendment)

Hendricks K (1999) Fumonisins and neural tube defects in south Texas. Epidemiology 10:198-200

Henry WB, Williams WP, Windham GL, Hawkins LK (2009) Evaluation of maize inbred lines for resistance to Aspergillus and Fusarium ear rot and mycotoxin accumulation. Agron J 101:1219-1226

Janse van Rensburg B (2011) Modelling the incidence of Fusarium and Aspergillus toxin-producing species in maize and sorghum in South Africa. PhD dissertation, University of the Free State, Bloemfontein, South Africa, pp. 110
Janse van Rensburg B, Mclaren NW, Flett BC, Schoeman A (2015) Fumonisin producing Fusarium spp. and fumonisin contamination in commercial South African maize. Eur J Plant Pathol 141:491-504

Kellerman TS, Marasas WFO, Thiel PG, Gelderblom WC, Cawood M, Coetzer JA (1990) Leukoencephalomalacia in two horses induced by oral dosing of fumonisin B1. Onderstepoort J Vet Res 57:269-275

Lanubile A, Maschietto V, de Leonardis S, Battilani P, Paciolla C, Marocco A (2015) Defense responses to mycotoxinproducing fungi Fusarium proliferatum, F. subglutinans, and Aspergillus flavus in kernels of susceptible and resistant maize genotypes. Mol Plant Microbe Interact 28:546-557

Lewis L, Onsongo M, Njapau H, Shurz-Rogers H, Luber G, Kieszak S, Nyamongo J, Backer L, Dahiye AM, Misore A, DeCock K, Rubin C, Kenya Aflatoxicosis Investigation Group (2005) Aflatoxin contamination of commercial maize products during an outbreak of acute aflatoxicosis in Eastern and Central Kenya. Environ Health Perspect 113:1763-1767

Li FQ, Yoshizawa T, Kawamura O, Luo XY, Li YW (2001) Aflatoxins and fumonisins in corn from the high-incidence area for human hepatocellular carcinoma in Guangxi, China. J Agric Food Chem 49:4122-4126

Marin S, Sanchis V, Ramos AJ, Vinas I, Magan N (1998) Environmental factors, in vitro interactions, and niche overlap between Fusarium moniliforme, F. proliferatum, and $F$. graminearum, Aspergillus and Penicillium species from maize grain. Mycol Res 102:831-837

Missmer SA, Suarez L, Felkner M, Wang E Jr, Merrill AH, Rothman KJ, Hendricks KA (2006) Exposure to fumonisins and the occurrence of neural tube defects along the Texas-Mexico border. Environ Health Perspect 114:237-241

Munkvold GP (2003) Cultural and genetic approaches to managing mycotoxins in maize. Annu Rev Phytopathol 41:99-116

Ncube E, Flett BC, Waalwijk C, Viljoen A (2011) Fusarium spp. and levels of fumonisins in maize produced by subsistence farmers in South Africa. S Afr J Sci 107:1-7

Parsons MW, Munkvold GP (2010) Associations of planting date, drought stress, and insects with Fusarium ear rot and fumonisin B1 contamination in California maize. Food Addit Contam 27:591-607

Parsons MW, Munkvold GP (2012) Effects of planting date and environmental factors on Fusarium ear rot symptoms and fumonisin B1 accumulation in maize grown in six North American locations. Plant Pathol 61:1130-1142

Payne R, Murray DA, Harding SA, Baird DB, Soutar DM (2012) An introduction to GenStat for Windows, 15th edn. VSN International, Hemel Hempstead

Purchase JL, Hatting H, Van Deventer CS (2000) Genotype x environment interaction of winter wheat (T. aestivum) in South Africa: stability analysis of yield performance. S Afr J Plant Soil 17:101-107

Ramirez ML, Pascale M, Chulze S, Reynoso MM, March G, Visconti A (1996) Natural occurrence of fumonisins and their correlation to Fusarium contamination in commercial corn hybrids growth in Argentina. Mycopathologia 135:29-34 
Rheeder JP, Marasas WFO, Van Wyk PS, Du Toit W, Pretorius AJ, Van Schalkwyk DJ (1990) Incidence of Fusarium and Diplodia species and other fungi in naturally infected grain of South African maize cultivars. Phytophylactica 22:97-102

Rheeder JP, Marasas WFO, Thiel PG, Sydenham EW, Shephard GS, Van Schalkwyk DJ (1992) Fusarium moniliforme and fumonisins in corn in relation to human esophageal cancer in Transkei. Phytopathology 82:353-357

Ritchie SW, Hanway JJ, Benson GO (1993) How a corn plant develops. Iowa State University Special Report No. 48

Robertson LA, Kleinschmidt CE, White DG, Payne GA, Maragos CM, Holland JB (2006) Heritabilities and correlations of Fusarium ear rot resistance and fumonisin contamination resistance in two maize populations. Crop Sci 46:353-361

Robertson-Hoyt LA, Betran J, Payne GA, White DG, Isakeit T, Maragos CM, Molnar TL, Holland JB (2007) Relationships among resistances to Fusarium and Aspergillus ear rots and contamination by fumonisin and aflatoxin in maize. Phytopathology 97:311-317

Rose LJ, Mouton M, Beukes I, Flett BC, van der Vyver C, Viljoen A (2016) Multi-environment evaluation of maize inbred lines for resistance to Fusarium ear rot and fumonisins. Plant Dis 100:2134-2144

Shephard GS (2008) Impact of mycotoxins on human health in developing countries. Food Addit Contam 25:146-151

Shephard GS, Marasas WFO, Leggott NL, Yazdanpanah H, Rahimian H, Safavi N (2000) Natural Occurrence of Fumonisins in Corn from Iran. $\mathrm{J}$ Agri Food Chem 48:1860-1864

Shephard GS, Marasas WFO, Burger HM, Somdyala NIM, Rheeder JP, van der Westhuizen L, Gatyeni P, Van Schalkwyk DJ (2007) Exposure assessment for fumonisins in the former Transkei region of South Africa. Food Addit Contam 24:621-629
Small IM, Flett BC, Marasas WFO, McLeod A, Stander MA, Viljoen A (2012) Resistance in maize inbred lines to Fusarium verticillioides and fumonisin accumulation in South Africa. Plant Dis 96:881-888

Wicklow DT, Horn BW, Shotwell OL, Hesseltine CW, Caldwell RW (1988) Fungal interference with Aspergillus flavus infection and aflatoxin contamination of maize grown in a controlled environment. Phytopathology 78:68-74

Williams JH, Phillips TD, Jolly PE, Stiles JK, Jolly CM, Aggarwal D (2004) Human aflatoxicosis in developing countries: a review of toxicology, exposure, potential health consequences, and interventions. Am J Clin Nutr 80:1106-1122

Wisser RJ, Balint-Kurti PJ, Nelson RJ (2006) The genetic architecture of disease resistance in maize: a synthesis of published studies. Phytopathology 96:120-129

Xiang K, Zhang ZM, Reid LM, Zhu XY, Yuan GS, Pan GT (2010) A meta-analysis of QTL associated with ear rot resistance in maize. Maydica 55:281-290

Yan W (2001) GGE biplot—a windows application for graphical analysis of multi-environment trial data and other types of two way data. Agron J 93:1111-1118

Yan W, Kang M (2003) GGE biplot analysis: a graphical tool for breeders, geneticists and agronomists. CRC Press, Boca Raton, p 271

Yan W, Rajcan I (2002) Biplot analysis of test sites and trait relations of soybean in Ontario. Crop Sci 42:11-20

Yan W, Hunt LA, Sheng Q, Szlavnics Z (2000) Cultivar evaluation and mega-environment investigation based on the GGE Biplot. Crop Sci 40:597-605

Zummo N, Scott GE (1992) Interaction of Fusarium moniliforme and Aspergillus flavus on kernel infection and aflatoxin contamination in maize ears. Plant Dis 76:771-773 